\title{
The United States Transuranium and Uranium Registries: Fifty-year History of Actinide Biokinetic Research
}

\author{
Maia Avtandilashvili ${ }^{1 *}$, Stacey L. McComish ${ }^{1}$, and Sergei Y. Tolmachev ${ }^{1}$ \\ ${ }^{1}$ U.S. Transuranium and Uranium Registries, College of Pharmacy and Pharmaceutical Sciences, \\ Washington State University, 1845 Terminal Drive, Suite 201, Richland 99354, WA, USA
}

\section{Introduction}

Designed as a program to improve radiation protection of nuclear workers, the U.S. Transuranium and Uranium Registries (USTUR) studies the biokinetics and internal dosimetry of actinides (uranium, plutonium, and americium) in occupationally exposed Registrants who volunteer portions of their bodies, or their whole bodies, for scientific use posthumously [1]. The USTUR is an invaluable national and international resource for testing biokinetic models and improving the application of bioassay data to estimate tissue doses.

Established as the National Plutonium Registry (NPR) in 1968 by the U.S. Atomic Energy Commission (AEC), today, the USTUR is one of the longest-operating research programs funded by the U.S. Department of Energy (DOE). Since 1992, the Registries is a grant-funded program operated by College of Pharmacy and Pharmaceutical Sciences at Washington State University (Fig 1).

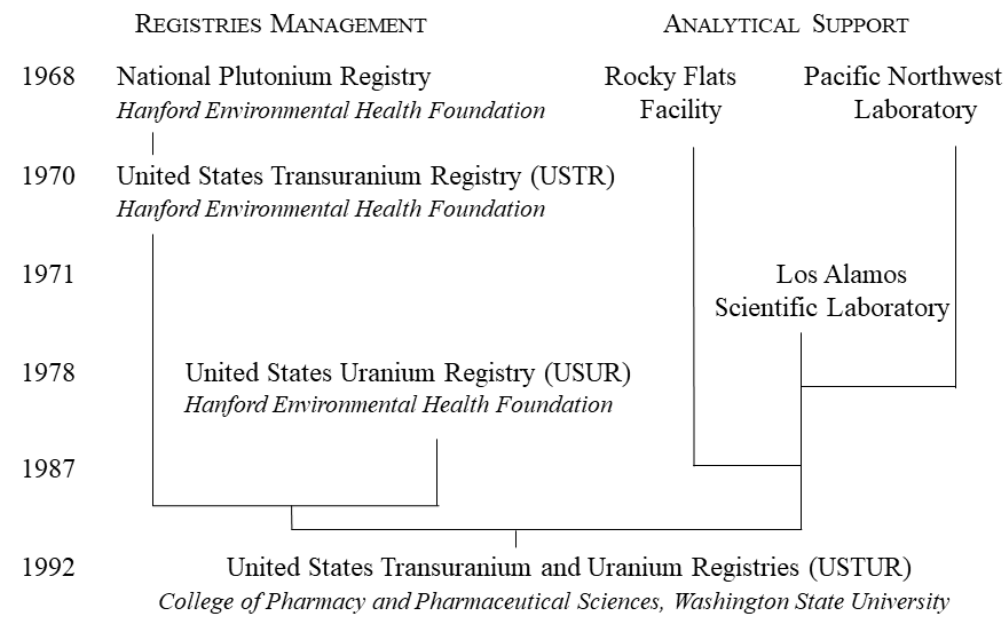

Fig. 1. Genealogy of the USTUR.

\footnotetext{
${ }^{*}$ Corresponding author: m.avtandilashvili@,wsu.edu
} 


\section{USTUR Registrants}

Currently, the USTUR retains records and data for 310 partial-body donors, 46 whole-body donors, and 33 living Registrants. These individuals typically worked at defence nuclear facilities where plutonium, americium, or uranium were processed (Fig 2).

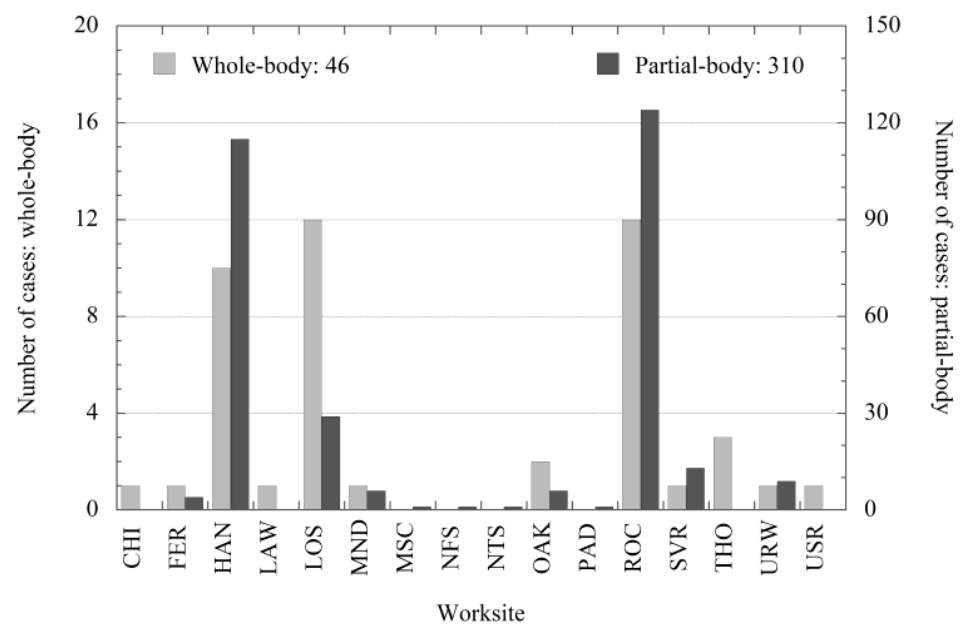

Fig. 2. USTUR Registrants by worksites.

\section{Historical Landmarks}

First whole-body donation: USTUR Case 0102. The first whole-body donation to the Registries was in 1979. This individual had a known exposure to ${ }^{241} \mathrm{Am}$ [2]. Half of the skeleton was analyzed, and the remaining half was used to make in vivo calibration phantoms of skull, torso, arm and leg, which have been made available to other scientists and are used worldwide [3,4].

The Atomic Man: USTUR Case 0246. This partial-body donor is known to have had the largest recorded intake of ${ }^{241} \mathrm{Am}$ [5]. An explosion of an ion-exchange column resulted in an estimated uptake of $40 \mathrm{MBq}$. He was heavily chelated with $\mathrm{Ca} / \mathrm{Zn}$-DTPA. This treatment reduced systemic deposition of ${ }^{241} \mathrm{Am}$ to $0.54 \mathrm{MBq}$ and is believed to have saved his life.

Thorotrast study: USTUR Case 1001. This whole-body donor was medically exposed to Thorotrast ${ }^{\circledR}$. Post-mortem analyses of tissues from this individual provided a unique opportunity to study the distribution and biokinetics of thorium [6].

These three USTUR cases were described in detail in four special issues of the Health Physics journal.

\section{Research}

The uniqueness of the USTUR lies in its ability to link thoroughly documented exposure, work history, medical, industrial hygiene, and bioassay data with precise postmortem measurements of the content and distribution of radionuclides in the human body. Historically, the research at the USTUR has focused on studying long-term retention and distribution of uranium, thorium, plutonium, and americium in the human body and biokinetic modelling of these elements. Post-mortem radiochemical analyses of tissues obtained at autopsy, especially those from the whole-body donors, allow the USTUR to 
significantly improve our knowledge of the distribution and long-term retention of actinides in the human body and have helped to parameterize biokinetic constants for these radioactive elements. During the last decade, the USTUR research was expanded to include modelling of actinide decorporation therapy and evaluation of uncertainties in organ dose estimates. Most recently, the USTUR explored opportunities to study beryllium and other non-radioactive materials in the human body. A few examples of recent USTUR research include evaluation of long-term plutonium retention in the upper airways to quantify plutonium 'bound' fraction [7], modelling of enriched uranium hexafluoride inhalation [8], and development of a system of compartmental models for plutonium decorporation [9].

The USTUR has published over 300 scientific papers. The Registries' research findings have contributed to five reports published by the National Council on Radiation Protection and Measurements (NCRP) and eight International Commission on Radiological Protection (ICRP) publications including the upcoming Occupational Intakes of Radionuclides, Part 4. A special issue of the Health Physics journal dedicated to USTUR research is currently in production.

\section{Conclusions}

The year 2018 marks 50 years of research at the U.S. Transuranium and Uranium Registries. The USTUR is the only program worldwide that can study biokinetics and dosimetry of internally deposited actinides this comprehensively. The USTUR serves as a source for both scientific research and public information regarding the radiobiology, biokinetics and dosimetry of the actinide elements in humans. Clearly, the USTUR's accomplishments could happen only because of our Registrants - without whom nothing would be possible.

\section{References}

1. The United States Transuranium and Uranium Registries. https://ustur.wsu.edu/

2. G. R. Roessler. Health Phys. 49, 559 (1985).

3. G. H. Kramer, B. Hauck, K. Capello et al. Health Phys. 101, 248 (2011).

4. P. Nogueira, W. Ruhm, M.A. Lopez et al. Radiation Meas. 82, 64 (2015).

5. R. E. Toohey, R. L. Kathren. Health Phys. 69, 310 (1995).

6. R. L. Kathren, R. L. Hill. Health Phys. 63, 72 (1992).

7. M. Puncher, A. Birchall, S. Y. Tolmachev. Radiat. Prot. Dosim. 176, 50 (2017).

8. M. Avtandilashvili, M. Puncher, S. L. McComish, S. Y. Tolmachev. J. Radiol. Prot. 35, 129 (2015).

9. S. Dumit, M. Avtandilashvili, S. L. McComish, D. J. Strom, G. Tabatadze, S. Y. Tolmachev. Radiat. Res. (submitted). 